\title{
Impact of Filter Cigarette Smoking on Lung Cancer Histology ${ }^{1}$
}

\author{
Steven D. Stellman, Ph.D., M.P.H., ${ }^{* 2}$ Joshua E. Muscat, M.P.H., ${ }^{*}$ Dietrich Hoffmann, Ph.D., $\dagger$ and \\ Ernst L. Wynder, M.D.*
}

*Division of Epidemiology and †Division of Environmental Carcinogenesis, The American Health Foundation, New York, New York 10017

Background. The rates of lung adenocarcinoma cancer have risen more rapidly than the rates of lung squamous cell cancer over the past 2 decades.

Methods. A case-control study was carried out to assess the impact of long-term filter cigarette smoking on the risk of squamous cell carcinoma (SCC) and adenocarcinoma (AC) of the lung.

Results. Odds ratios for SCC among subjects who had smoked only filter cigarettes were reduced relative to lifetime nonfilter cigarette smokers by $30 \%$ for men and by $60 \%$ for women, but no risk reduction was observed for $\mathrm{AC}$ of the lung.

Conclusion. The predominance of AC over SCC may be due in part to the fact that smokers of very low yield cigarettes tend to compensate for the lower nicotine levels by inhaling more deeply and frequently, leading to greater exposure of the peripheral lung to the carcinogens in tobacco smoke, and in part to the increased concentration of nitrosamines that preferentially produce AC in laboratory animals. $\odot 1997$ Academic Press

Key Words: lung cancer; histology; smoking; filter; nicotine.

\section{INTRODUCTION}

The incidence of lung cancer in the United States increased substantially over the past several decades. Using data from the $\mathrm{SEER}^{3}$ cancer registries, Devesa et al. showed that the trends in lung cancer incidence varied by gender, race, and histologic type [1]. The incidence of adenocarcinoma (AC) increased by $111 \%$ for

\footnotetext{
1 This work was supported by USPHS Grants CA-32617, CA68384, CA-29580, and CA-17613 from the National Cancer Institute.

${ }^{2}$ To whom reprint requests should be addressed at American Health Foundation, 320 E. 43 Street, New York, NY 10017.

${ }^{3}$ Abbreviations used: AC, adenocarcinoma; AHF, American Health Foundation; BaP, benzo[a]pyrene; FTC, Federal Trade Commission; NNK, 4-(methylnitrosamino)-1-(3-pyridyl)-1-butanone; OR, odds ratio; PAH, polynuclear aromatic hydrocarbons; SCC, squamous cell carcinoma; "tar," that portion of the condensate from tobacco smoke trapped on a Cambridge filter, from which nicotine and moisture have been subtracted; SEER, Surveillance, Epidemiology and End Results Program of the National Cancer Institute; TSNA, tobacco-specific nitrosamines.
}

white men and by $220 \%$ for white women between 1969-1971 and 1984-1986. In contrast, over the same 15-year time period, the rate of squamous cell carcinoma (SCC) increased by $25 \%$ for white men and $156 \%$ for white women. Among blacks, the trends were similar. These rates have decelerated greatly during the most recent 5-year period, 1984-1986 to 1989-1991. SCC began to decline among both white and black males, and AC decreased slightly among black males, but histology-specific rates of both SCC and AC continued to increase among white males and among all females (National Cancer Institute, unpublished data).

While it is well established that cigarette smoking is the major cause of lung cancer, the marked differences in the rates of AC and SCC as well as their different patterns of change among men compared with women suggest that exposure to cigarette smoke carcinogens is changing in complex ways.

The FTC-rated yields of "tar" and nicotine in smoke both decreased by at least $60 \%$ since 1950 due largely to introduction of filters (Fig. 1). Because cigarette "tar" contains numerous carcinogens, it is plausible that the secular changes in lung cancer rates are the consequences of changes in the formulation and manufacture of tobacco products in recent decades. Previous case-control and cohort studies found the risk of lung cancer for smoking lower "tar" cigarettes to be significantly lower than for smoking high-"tar" cigarettes [2]. However, this conclusion was based on studies of smokers of cigarettes that contained much higher "tar" levels than those commonly smoked during recent decades [3].

The extent of cancer risks associated with smoking the newer, lower "tar" cigarettes have not been established because these cigarettes were only recently introduced into the market, whereas lung cancer has a latency period measurable in decades. It can be expected that lower yield cigarettes will have health consequences that differ from those of higher yield products because of their altered smoke chemistry. Figure 2 shows that a long-term decline in PAHs has been accompanied by higher smoke concentrations of TSNAs such as NNK, which resulted from an increase in the nitrate content of cigarette tobacco from about 0.5 to $1.3-1.5 \%[4,5]$. PAHs and TSNAs are both complete 


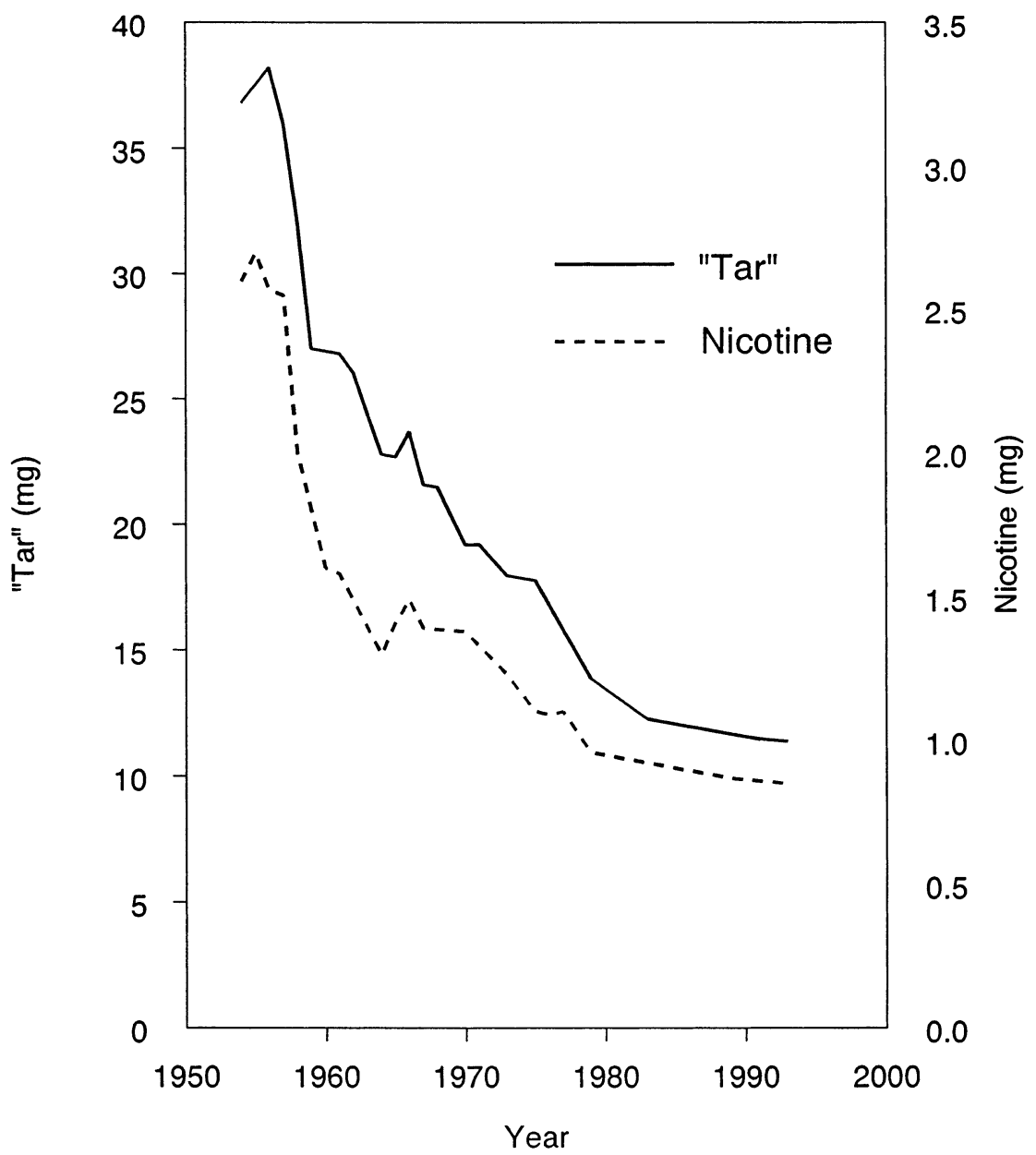

FIG. 1. 1954-1993 sales-weighted average "tar" and nicotine deliveries of all domestic brands of cigarettes on the U.S. market.

lung carcinogens but with differing effects on animal models. Intratracheally instilled $\mathrm{BaP}$ and other carcinogenic PAHs induce squamous cell carcinoma in rats and hamsters [6], and workers who are exposed to aerosols from combustion products with high concentrations of carcinogenic PAHs develop predominantly

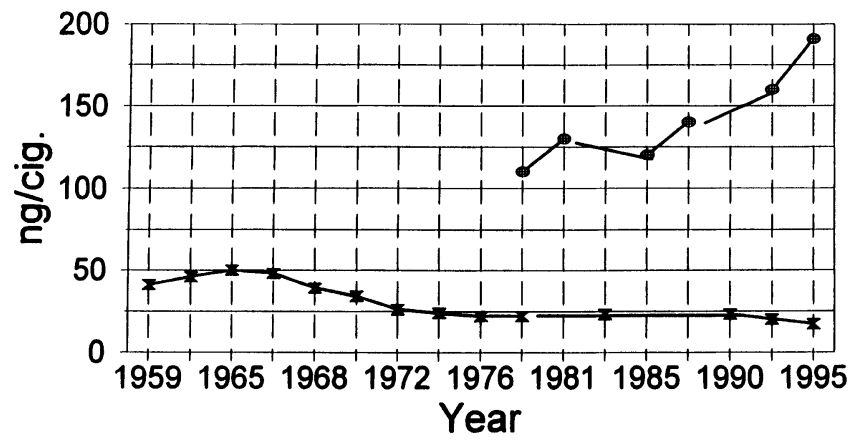

\section{$\mathrm{BaP} \rightarrow \mathrm{NNK}$}

FIG. 2. BaP, 1959-1995, and NNK, 1978-1995, in the smoke of a leading U.S. nonfilter cigarette.
SCC $[7,8]$. NNK induces primarily adenoma and adenocarcinoma of the lung in mice, rats, and Syrian golden hamsters independently of site of application [9]. It is thus possible that smokers who switch to lower yield cigarettes or who smoke them exclusively may be at risk for different types of lung cancer compared with smokers of higher yield cigarettes. We therefore studied the risk of the two most common histologic types of lung cancer, SCC and AC, in relation to long-term filter cigarette smoking.

\section{MATERIALS AND METHODS}

Beginning in 1977, a hospital-based case-control study of risk factors for lung cancer was carried out in New York and several other cities. The methodology for this study has been previously described [10,11]. In brief, after signing a consent form approved by the local Institutional Review Board, newly diagnosed incident cases of lung cancer were interviewed by trained personnel using structured questionnaires. Lifestyle habits such as tobacco smoking, alcohol consumption, occupational histories, and occupational exposures 
were recorded. The histological types of lung cancer were obtained from surgical pathology reports. Controls were patients with illnesses unrelated to cigarette smoking, matched to cases on age ( \pm 5 years), sex, hospital, and date of admission ( \pm 2 months). A total of 5,386 lung cancer patients $(1,797$ squamous cell and 2,314 adenocarcinomas) and 5,632 controls were interviewed.

The number of years that each brand of cigarette was smoked was recorded, along with amount smoked daily. Cigarette smokers were classified according to whether subjects had smoked nonfilter cigarettes exclusively, had switched from smoking nonfilter to filter cigarettes, or had smoked filter cigarettes exclusively.

The ORs associated with various histories of filter cigarette smoking were calculated using logistic regression, adjusting for age, education, and number of cigarettes smoked per day, in separate strata by gender and histologic type of tumor. For those calculations in which risks were compared among persons with different smoking histories, the reference group consisted of lifetime smokers of nonfilter cigarettes, rather than nonsmokers.

\section{RESULTS}

Our analyses are based on 1,366 males and $431 \mathrm{fe}-$ males with SCC, and 1,332 males and 982 females with $\mathrm{AC}$ (Tables 1 and 2) AC was more common than squamous cell carcinoma among both men and women below the age of 44 compared with older age groups. The histologic distributions did not differ significantly between black and white subjects.

Among lung cancer cases, those with adenocarci-

\section{TABLE 1}

Frequency of Squamous Cell Carcinoma and Adenocarcinoma of the Lung by Age, Education, and Race: American Health Foundation, Males, 1977-1995

\begin{tabular}{lccc}
\hline & $\begin{array}{c}\text { Squamous } \\
\text { cell carcinoma } \\
N=1,366 \\
(\%)\end{array}$ & $\begin{array}{c}\text { Adenocarcinoma } \\
N=1,332 \\
(\%)\end{array}$ & $\begin{array}{c}\text { Controls } \\
N=3,442 \\
(\%)\end{array}$ \\
\hline Age (years) & & & \\
$\leqslant 44$ & 5.1 & 9.1 & 8.5 \\
$45-54$ & 18.5 & 21.3 & 19.2 \\
$55-64$ & 40.1 & 38.1 & 39.5 \\
$65-74$ & 31.0 & 26.4 & 28.3 \\
$75+$ & 5.2 & 5.2 & 4.5 \\
Years of education & & & \\
$\leqslant 11$ & 37.9 & 27.5 & 24.3 \\
12 & 28.2 & 26.6 & 26.1 \\
$13-15$ & 14.0 & 18.8 & 16.5 \\
$16+$ & 19.9 & 27.1 & 33.1 \\
Race & & & \\
White & 89.8 & 89.4 & 92.6 \\
Black & 9.5 & 8.8 & 7.0 \\
Other & 0.7 & 1.8 & 0.4 \\
\hline
\end{tabular}

\section{TABLE 2}

Frequency of Squamous Cell Carcinoma and Adenocarcinoma of the Lung by Age, Education, and Race: American Health Foundation, Females, 1977-1995

\begin{tabular}{lccc}
\hline & $\begin{array}{c}\text { Squamous } \\
\text { cell carcinoma } \\
N=431 \\
(\%)\end{array}$ & $\begin{array}{c}\text { Adenocarcinoma } \\
N=982 \\
(\%)\end{array}$ & $\begin{array}{c}\text { Controls } \\
=2,190 \\
(\%)\end{array}$ \\
\hline Age (years) & & & \\
$\leqslant 44$ & 6.5 & 10.4 & 9.7 \\
$45-54$ & 20.4 & 22.2 & 23.1 \\
$55-64$ & 32.7 & 33.8 & 34.7 \\
$65-74$ & 32.0 & 28.6 & 27.8 \\
$75+$ & 8.4 & 5.0 & 4.8 \\
Years of education & & & \\
$\leqslant 11$ & 25.1 & 20.2 & 19.2 \\
12 & 42.0 & 41.7 & 37.1 \\
$13-15$ & 19.3 & 21.0 & 21.1 \\
$16+$ & 13.7 & 17.1 & 22.6 \\
Race & & & \\
White & 91.4 & 91.2 & 93.9 \\
Black & 7.9 & 7.9 & 5.9 \\
Other & 0.7 & 0.8 & 0.2 \\
\hline
\end{tabular}

noma were more likely to have never smoked than those with SCC. Fewer than $2 \%$ of the men and fewer than $6 \%$ of the women with SCC had never smoked, while $5.4 \%$ of the men and $15.0 \%$ of the women with AC were never-smokers. Among the cigarette smokers, over $43 \%$ of the men and $33 \%$ of the women with SCC smoked two or more packs of cigarettes per day, compared with $41 \%$ of the men and $29 \%$ of the women with AC who were heavy smokers. SCC was associated with higher odds ratios than was AC for both current smokers and ex-smokers: current smokers $\mathrm{OR}=32.1$ vs 9.9 for males, 28.3 vs 8.9 for females; ex-smokers $\mathrm{OR}=$ 14.4 vs 4.3 for males, 11.0 vs 4.1 for females.

Figures 3 and 4 show classical dose-response progressions with regard to number of cigarettes smoked per day for males and females, respectively. Figures 5 and 6 present ORs and 95\% confidence intervals for both types of lung cancer according to lifetime history of filter cigarette smoking, adjusted for age, education, and number of cigarettes smoked per day. For males, the risk of SCC was lower among smokers who had switched from nonfilter to filter cigarettes $(\mathrm{OR}=0.9$; 95\% CI 0.7-1.2) and lower still for lifetime filter cigarette smokers $(\mathrm{OR}=0.8 ; 95 \% \mathrm{CI} 0.5-1.2)$. A pattern of reduced risk for SCC was also observed among women, with significantly reduced risks among women who had switched from nonfilters to filters $(\mathrm{OR}=0.6 ; 95 \%$ CI 0.3-0.98) and still lower risks among lifetime filter cigarette smokers $(\mathrm{OR}=0.4 ; 95 \% \mathrm{CI} 0.2-0.8)$. By contrast, the AC risks were not significantly reduced either for men or for women. Polychotomous logistic regression using the common set of controls showed that the logistic regression coefficients for SCC and AC among women were significantly different $(P<0.01)$. 


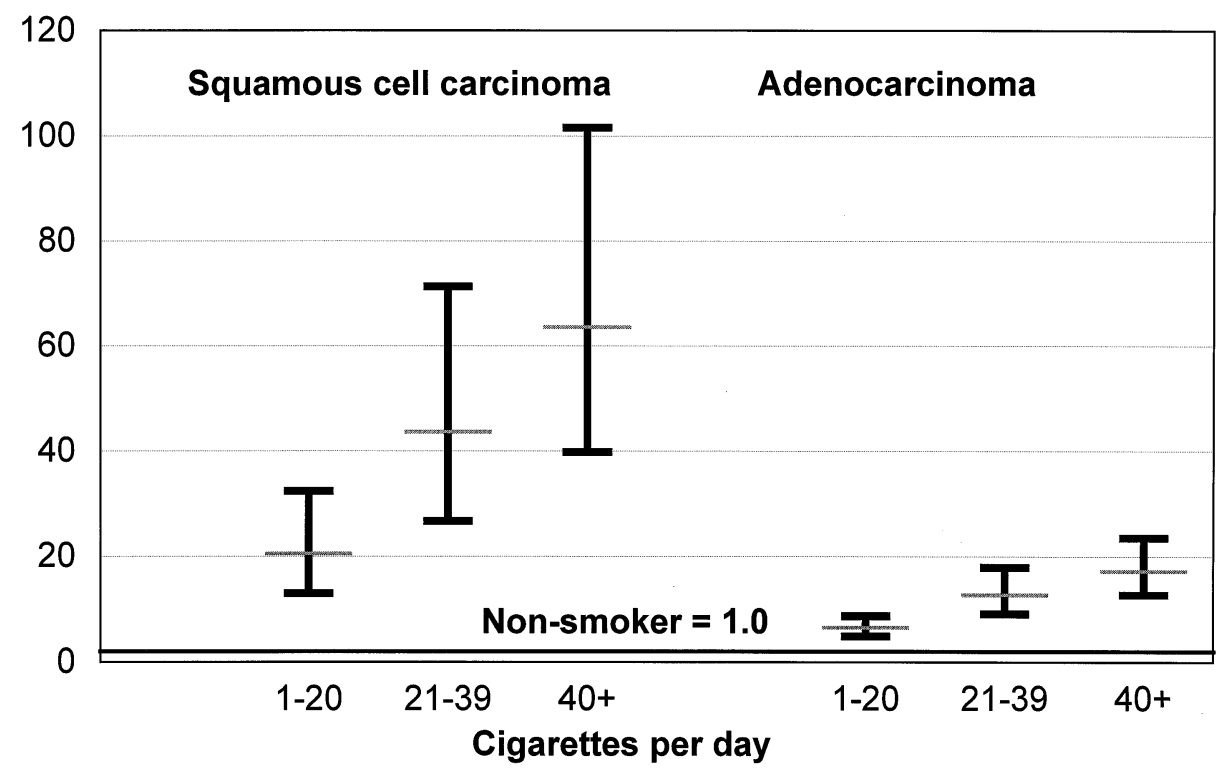

FIG. 3. Odds ratios for lung cancer among current smokers interviewed in American Health Foundation (AHF) study by amount smoked per day and histologic type, males, 1977-1995.

\section{DISCUSSION}

The belief that lung cancer risk should increase in proportion to the "tar" content of cigarettes is supported empirically by many previous case-control and cohort studies of varying designs [2], including reports from our group in 1970 [12], 1977 [10], and 1979 [13]. However, past studies were based upon cohorts whose lifetime smoking history, especially in their early years of smoking, was weighted with cigarettes having up to four times the yield of both "tar" and nicotine of brands commonly smoked today. Since the 1950s the sales- weighted average "tar" and nicotine yields of U.S. cigarettes decreased from about 38 and $2.7 \mathrm{mg}$ to 12.0 and $0.95 \mathrm{mg}$, respectively [14] (Fig. 1) while the percentage of all cigarettes smoked in the United States that were filter-tipped cigarettes increased from $19 \%$ in 1955 to more than 97\% in 1992 [15].

The reduction in smoke yields, especially in nicotine, has led to "compensation," or behavioral adjustment by smokers of lower nicotine-yielding cigarettes in favor of greater puff frequency, puff volume, and deeper inhalation in order to achieve the desired physiological response to nicotine [16]. Wynder and Hoffmann have

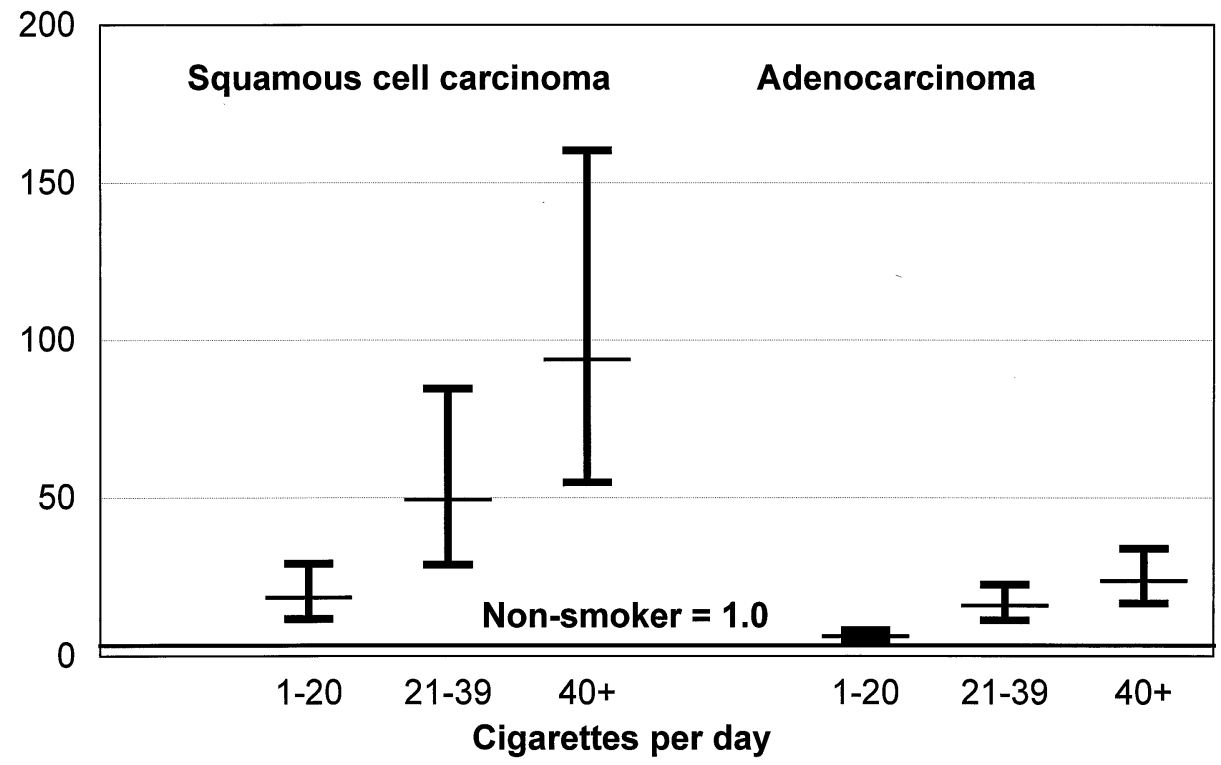

FIG. 4. Odds ratios for lung cancer among current smokers interviewed in AHF study by amount smoked per day and histologic type, females, 1977-1995. 


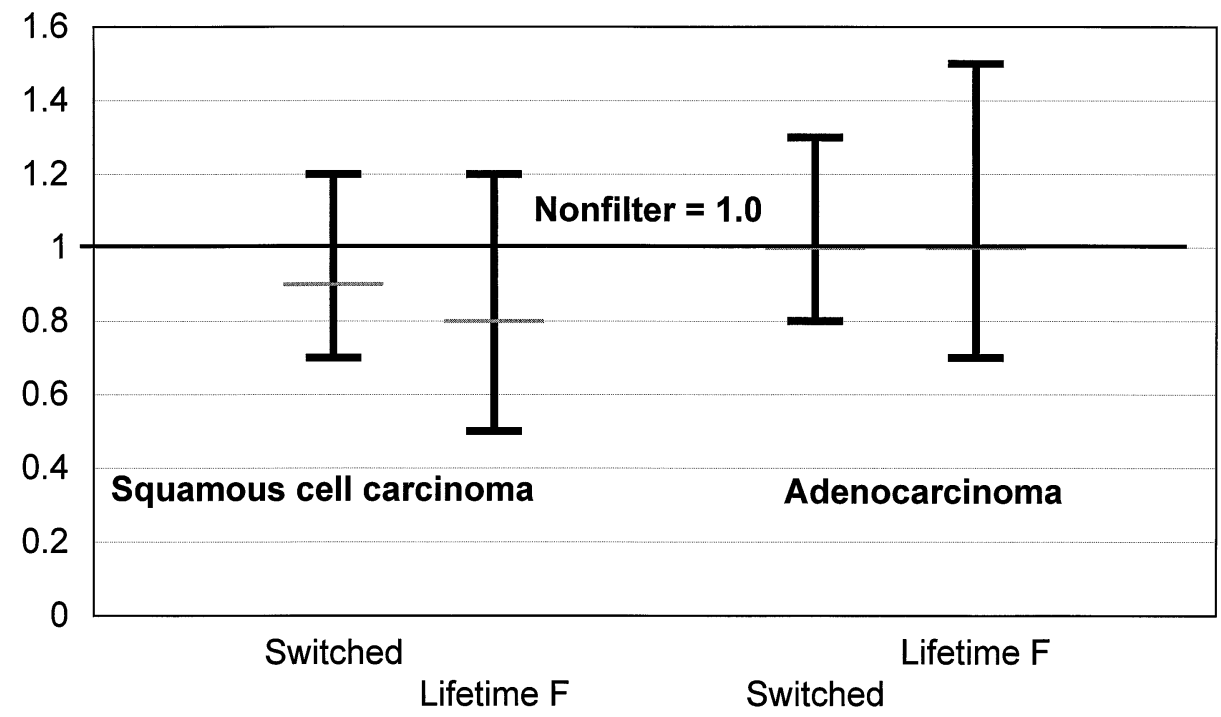

FIG. 5. Odds ratios for lung cancer among current smokers interviewed in AHF study by years of filter smoking and histologic type, adjusted for age, education, time period, and amount smoked per day, males, 1977-1995.

suggested that under these conditions, smoke particles are inhaled into the lung with greater velocity, and a greater proportion of them may bypass the major bronchi, depositing instead in the smaller airways and alveoli. This forced inhalation of the smoke aerosol opens the alveoli widely and facilitates the rapid satiation with nicotine [17]. The secondary and tertiary bronchi of the lung and the alveolar region also lack the defenses that are present in the major bronchi, i.e., ciliated epithelium and mucus-secreting cells. Therefore, the more peripheral bronchi are likely less resistant to the toxic and carcinogenic constituents of cigarette smoke.

It is noteworthy that most lung neoplasms among primary smokers of pipe tobacco and cigars are usually
SCCs arising from the major bronchi [18]. Cigars and pipes generate alkaline smoke with significant amounts of unprotonated nicotine which is rapidly absorbed through the oral mucosa. Therefore, in contrast to the smoker of low-yield cigarettes, cigar and pipe smokers do not "need" to inhale the smoke very deeply, and many do not inhale the smoke at all [19].

The shift toward AC may also be due in part to higher levels of organ-specific and carcinogenic TSNAs in cigarette smoke. As seen in Fig. 2, the per-cigarette amount of $\mathrm{BaP}$ (a surrogate for carcinogenic $\mathrm{PAH}$ ) in the smoke of the best-selling U.S. nonfilter cigarette declined from $52 \mathrm{ng}$ in 1965 to $18 \mathrm{ng}$ in 1995, whereas NNK, a surrogate for total TSNA, increased from 110 ng in 1978 to $191 \mathrm{ng}$ in 1995. Similar trends for NNK

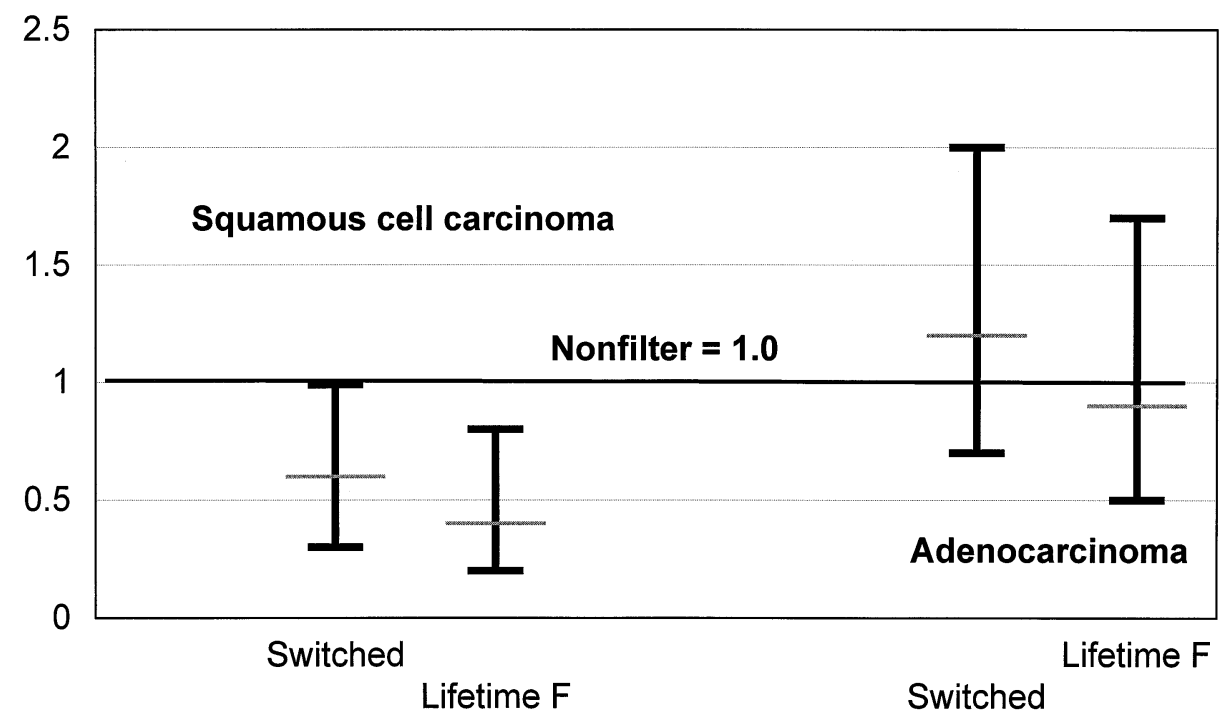

FIG. 6. Odds ratios for lung cancer among current smokers interviewed in AHF study by years of filter smoking and histologic type, adjusted for age, education, time period, and amount smoked per day, females, 1977-1995. 
were seen for the smoke of other cigarettes, including filter cigarettes.

Our findings, together with the observation by Thun and colleagues that lung cancer death rates among cigarette smokers in the 1982-1989 American Cancer Society cohort were twice those of smokers in the 19601966 cohort [20], strongly indicate that the lower yield cigarettes of today are not necessarily lower risk cigarettes, and emphasize the need for continued and widespread monitoring of smoking-related health risks [21].

\section{ACKNOWLEDGMENTS}

The authors express their gratitude to Pat Lamb for manuscript preparation and the following individuals and institutions: Elliot Strong, M.D., Newton Morton, M.D., Susan Harlap, M.D., Memorial Sloan-Kettering Cancer Center, New York; Ronald H. Blum, M.D., New York University Medical Center; Alfred I. Neugut, M.D., Ph.D., Columbia University School of Public Health, New York; Philip Witorsch, M.D., George Washington University Medical Center, Washington, DC; Edward Garrity Jr., M.D., Loyola University Hospital, Chicago; John Sharp, M.D., VA Medical Center, Hines, Illinois; Christine Johnson, Ph.D., Henry Ford Hospital, Detroit; Kanti Rai, M.D., Marc Citron, M.D., Long Island Jewish Medical Center, New Hyde Park, New York; Linga Ragu, M.D., Nassau County Medical Center, East Meadow, New York; James Colberg, M.D., Thomas Jefferson University Hospital, Philadelphia; and Paul Stolley, M.D., Hospital of the University of Pennsylvania, Philadelphia.

\section{REFERENCES}

1. Devesa SS, Shaw GL, Blot WJ. Changing pattern of lung cancer incidence by histological type. Cancer Epidemiol Biomark Prev 1991;1:29-34.

2. Stellman SD. Cigarette yield and cancer risk: evidence from case-control and prospective studies. In: Zaridze DG, Peto R, editors. Tobacco, a major international health hazard. Lyon: International Agency for Research on Cancer, 1986:197-209. [IARC Scientific Publication No. 74]

3. Stellman SD, Garfinkel L. Lung cancer risk is proportional to cigarette tar yield: evidence from a prospective study. Prev Med 1989;18:518-25.

4. Hoffmann D, Rivenson A, Murphy SE, et al. Cigarette smoking and adenocarcinoma of the lung: the relevance of nicotinederived $N$-nitrosamines. J Smoking Relat Disord 1993;4:165-90.

5. Hoffmann D, Hoffmann I. Recent developments in smokingrelated cancer research. J Smoking Relat Disord 1994;5:77-93.
6. Davis BR, Whitehead JK, Gill ME, et al. Response of rat lung to inhaled tobacco smoke with or without prior exposure to 3,4benzpyrene (BP) given by intratracheal instillation. Br J Cancer 1975;31:469-84.

7. International Agency for Research on Cancer. Polynuclear aromatic compounds, Part 2, Carbon blacks, mineral oils and some nitroarenes. Vol. 33. Lyon:IARC, 1984. [IARC monographs on the evaluation of the carcinogenic risk of chemicals to humans]

8. International Agency for Research on Cancer. Polynuclear aromatic compounds, Part 3, Industrial exposures in aluminum production, coal gasification, coke production, and iron and steel founding. Vol. 34. Lyon:IARC, 1984. [IARC monographs on the evaluation of the carcinogenic risk of chemicals to humans]

9. Hoffmann D, Brunnemann KD, Prokopczyk B, et al. Tobaccospecific $N$-nitrosamine and areca-derived $N$-nitrosamines: chemistry, biochemistry, carcinogenicity, and relevance to humans. J Toxicol Environ Health 1994;41:1-52.

10. Wynder EL, Stellman SD. Comparative epidemiology of tobaccorelated cancers. Cancer Res 1977;37:4608-22.

11. Wynder EL, Covey LS. Epidemiologic patterns in lung cancer by histological type. Eur J Cancer Clin Oncol 1987;23:1491-6.

12. Wynder EL, Mabuchi K, Beattie EJ. The epidemiology of lung cancer. J Am Med Assoc 1970;213:2221-8.

13. Wynder EL, Stellman SD. Impact of long-term filter cigarette usage on lung and larynx cancer risk: a case-control study. J Natl Cancer Inst 1979;62:471-7.

14. Hoffmann D, Hoffmann I, Wynder EL. Lung cancer and the changing cigarette. In: O'Neill IK, Chen JS, Bartsch H, editors. Relevance to human cancer of nitroso compounds. Lyon: International Agency for Research on Cancer, 1991:449-59. [IARC Scientific Publication No. 105]

15. U.S. Department of Agriculture. Percent of total cigarette production which are filter-tipped cigarettes. USDA-Foreign Tobacco 1993;8:40-1.

16. Wynder EL, Hoffmann D. Smoking and lung cancer: scientific challenges and opportunities. Cancer Res 1994;54:5284-95.

17. Burns DM. Cigarettes and cigarette smoking. Clin Chest Med 1991;12:631-42.

18. Higgins ITT, Mahan CM, Wynder EL. Lung cancer among cigar and pipe smokers. Prev Med 1988;17:116-28.

19. Armitage AK, Turner DM. Absorption of nicotine in cigarette and cigar smoke through the oral mucosa. Nature 1970;226: 1231-2.

20. Thun MJ, Day-Lally CA, Calle EE, Flanders WD, Heath CW. Excess mortality among cigarette smokers: changes in a 20-year interval. Am J Public Health 1995;85:1223-30.

21. Patel AR, Obrams GI. Adenocarcinoma of the lung: meeting report. Cancer Epidemiol Biomarkers Prev 1995;4:175-80. 